DOI 10.5216/ia.v46i3.67144

\title{
ENSINO DE HISTÓRIA E RELAÇÕES RACIAIS NA BNCC: INTERCULTURALIDADE FUNCIONAL E SUBORDINAÇÃO À PEDAGOGIA DAS COMPETÊNCIAS
}

\author{
Maria ApareCida Lima dos SANtos \\ Universidade Federal de Mato Grosso do Sul, Campo Grande, Mato Grosso do Sul, Brasil \\ Ana Rita LaRA de Oliveira \\ Universidade Federal de Mato Grosso do Sul, Campo Grande, Mato Grosso do Sul, Brasil
}

\begin{abstract}
Resumo: Apresentamos neste artigo, a partir de estudo de viés qualitativo e documental, a análise de alguns significantes relacionados à educação para as relações raciais que, abordados como híbridos, destacaram-se no processo de formulação da Base Nacional Comum Curricular (BNCC) ao apontarem para ocultamentos associados a projetos a ela subjacentes. Concluímos ressaltando que a substituição dos chamados enfoques predominantes pelo rol de competências na versão voltada ao Ensino Médio configura-se como indício do processo de recontextualização, que afasta o ensino de História tanto de sua função formativa quanto pedagógica e educativa ao exacerbar o pragmatismo subjacente à Pedagogia das Competências, fundamento central da BNCC.
\end{abstract}

Palavras-chave: Políticas Curriculares. Ensino de História. BNCC.

\section{INTRODUÇÃO}

Após a publicação da proposta elaborada para o componente curricular de História na Base Nacional Comum Curricular (BNCC) para o Ensino Médio, o intenso debate envolvendo historiadores, especialistas em ensino de História, profissionais vinculados à grande mídia e o público em geral tornou mais atual do que nunca a afirmação de Marc Ferro, o qual observou que a História, ontem como hoje, é vigiada devido à maior divulgação e acesso do cidadão comum às reflexões historiográficas (FERRO, 1989). Destacamos, nesse contexto, que é perceptível como essa vigilância torna-se redobrada quando abordamos as formulações curriculares que determinam o que deve ser ensinado.

No amplo debate que se seguiu ao lançamento da primeira versão em 2015 e sua substituição por um texto completamente novo, como terceira versão para consulta pública (abril de 2018), e, posteriormente, na versão homologada para o Ensino Médio (dezembro de 2018), delineou-se um cenário que permitiu ao grande público conhecer nuances dos jogos de poder entre, por um lado, o passado coletivo a consagrar e, por outro, em função do primeiro, da determinação dos princípios e concepções que, na contemporaneidade, devem guiar o ensino da História.

As críticas e ataques à primeira versão interpelaram, em especial, a centralidade das relações raciais na estruturação do currículo de História. A nova redação, que relegou a temática a segundo plano, na versão homologada, foi considerada por nós 
como sintomática de processos de disputa mais amplos e complexos dentro dos quais a proposta curricular de História precisa ser compreendida ao abordar a interculturalidade em perspectiva funcional, conforme veremos.

Assim, nosso estudo', que recaiu sobre o trecho destinado ao componente curricular de História para o Ensino Médio, procurou, a partir da análise de alguns significantes que se destacaram no processo e de alguns ocultamentos identificados, examinar as características dos projetos subjacentes a BNCC.

$\mathrm{Na}$ realização da investigação, pressupomos a BNCC como mecanismo discursivo que opera dentro de um regime de verdade a serviço da busca de hegemonia no campo educacional e social. Por esse ângulo, exacerba-se sua característica de prática cultural e de lugar de enunciação contextualizados em disputas (MACEDO, 2006). Abordados como espaços de poder, os documentos curriculares funcionam como um sistema de significações onde os sentidos são produzidos pelos sujeitos (LOPES; MACEDO, 2011) e, como fruto de políticas públicas que constituem um movimento institucional na busca de viabilizar um discurso oficial sobre educação, projetam identidades pedagógicas e orientam a produção do conhecimento oficial (LOPES, 2002).

Para apresentar um pequeno excerto do estudo desenvolvido, organizamos o texto em três partes. Na primeira, abordamos a BNCC no contexto das chamadas reformas curriculares, os fundamentos teórico-metodológicos de nosso estudo, bem como as temáticas elencadas para os segmentos de Educação Infantil e Ensino Fundamental, com o objetivo de fornecer uma visão panorâmica do documento. Em seguida, inserimos o trecho reservado ao componente curricular de História no Ensino Médio e a análise empreendida. Na última parte, tecemos nossas considerações finais.

\section{ENSINO DE HISTÓRIA NO CONTEXTO DAS REFORMAS CURRICULARES}

Os documentos curriculares contemporâneos inserem-se nas reformas empreendidas nas últimas quatro décadas em diferentes países. Essas reformas foram marcadas pelos princípios propugnados pelas conferências mundiais de Educação desde, pelo menos, 1990, ocasião em que o Banco Mundial assumia o comando da Educação no mundo norteado pelas orientações do Consenso de Washington, "um consenso entre o FMI, Banco Mundial e o Departamento do Tesouro dos Estados Unidos em relação às políticas 'certas' para os países em desenvolvimento" (STIGLITZ, 2002, p. 43 apud SAWAYA, 2014, p. 130-131), dentre eles, o Brasil. O Consenso destacou-se:

[...] pela defesa das políticas neoliberais: a liberdade de fluxo comercial com a diminuição ou extinção de barreiras alfandegárias, tarifárias e das políticas de manipulação das taxas de câmbio; liberdade para entrada e saída de fluxos financeiros; privatização das empresas estatais e mudança do papel do Estado de "desenvolvimentista", tradicionalmente com papel ativo - seja pela definição de estratégias, seja como investidor direto -, para um Estado regulador, como agente responsável apenas em criar e manter o "ambiente institucional" necessário para atração do IDE ${ }^{2}$ (SAWAYA, 2014, p. 131-131). 
SANTOS, M. A. L. dos; OLIVEIRA, A. R. L. de.

Realizado também no ano de 1990, o Consenso enfatizou a necessidade de diminuição dos índices mundiais de pobreza pela metade, fornecendo subsídios ao Banco Mundial na defesa da tese da Educação como determinante de inclusão social na perspectiva da teoria do capital humano, que preconizava o investimento em Educação como fator para o desenvolvimento econômico (MENEZES, 2012).

Esses aspectos contextuais que marcaram a formulação da BNCC foram considerados na análise do documento, em abordagem qualitativa (GHEDIN; FRANCO, 2011), de caráter documental (SÁ-SILVA; ALMEIDA; GUINDANI, 2009). No presente estudo, observamos como alguns significantes são operados em meio a movimentos de hibridação, os quais são compreendidos como "processos socioculturais nos quais estruturas ou práticas discretas, que existiam de forma separada, se combinam para gerar novas estruturas, objetos e práticas" (GARCÍA CANCLINI, 2015, p. XIX)

Para dar visibilidade ao conjunto das versões da BNCC dentro do qual operamos nosso recorte, organizamos o quadro cronológico abaixo, assinalando quais documentos foram objeto da reflexão apresentada neste artigo.

Quadro 1: Cronologia de produção das versões da BNCC voltadas às etapas de Educação Infantil (EI) e Ensino Fundamental (EF) (BRASIL, 2017), e Ensino Médio (EM) (BRASIL, 2018b, 2018c).

\begin{tabular}{|c|c|c|c|c|c|}
\hline \multirow{2}{*}{ Ano } & \multirow{2}{*}{$\begin{array}{l}\text { Versão do } \\
\text { documento }\end{array}$} & \multicolumn{3}{|c|}{ Segmentos } & \multirow[b]{2}{*}{ Informações de identificação } \\
\hline & & El & $\mathrm{EF}$ & EM & \\
\hline $2002-2015$ & \multicolumn{4}{|c|}{$\begin{array}{c}\text { MEC - plano das discussões sobre } \\
\text { currículo }\end{array}$} & \\
\hline $\begin{array}{l}2013 \text { (jun.) } \\
2015 \text { (fev.) }\end{array}$ & $\begin{array}{c}\text { Trabalho do GT- } \\
\text { DIAd }\end{array}$ & $\mathrm{X}$ & $\mathrm{x}$ & $\mathrm{x}$ & - \\
\hline 2015 (set.) & $\begin{array}{c}\text { 1.a versão } \\
\text { (BRASIL, 2015) }\end{array}$ & $x$ & $\mathrm{X}$ & $x$ & $\begin{array}{l}1^{\text {a }} \text { versão da BNCC apresentada à público } \\
\text { para debate e que foi considerada para este } \\
\text { artigo. }\end{array}$ \\
\hline 2016 (mai.) & $\begin{array}{c}\text { 2. }{ }^{\text {a versão }} \\
\text { (BRASIL, 2016) }\end{array}$ & $\mathrm{X}$ & $\mathrm{X}$ & $\mathrm{X}$ & 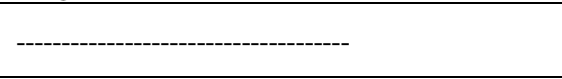 \\
\hline 2017 (fev.) & ---- & - & - & - & Reforma do Ensino Médio. \\
\hline 2017 (abr.) & $\begin{array}{l}\text { 3. a versão El e } \\
\text { EF } \\
\text { (homologada) }\end{array}$ & $\mathrm{X}$ & $\mathrm{x}$ & - & $\begin{array}{l}\text { Resolução CNE/CP 2/2017- Institui e } \\
\text { orienta a implantação da Base Nacional } \\
\text { Comum Curricular, a ser respeitada } \\
\text { obrigatoriamente ao longo das etapas e } \\
\text { respectivas modalidades no âmbito da } \\
\text { Educação Básica. }\end{array}$ \\
\hline 2018 (abr.) & 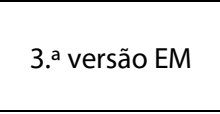 & - & - & $\mathrm{x}$ & $\begin{array}{l}\text { Submetida às audiências públicas, } \\
\text { recebendo contribuições via sistema } \\
\text { eletrônico. }\end{array}$ \\
\hline 2018 (dez.) & $\begin{array}{l}\text { 3. a versão EM } \\
\text { (homologada) } \\
\text { (BRASIL, 2018b) }\end{array}$ & - & - & $\mathrm{x}$ & $\begin{array}{l}\text { Resolução CNE/CP 4/2018 - Institui a Base } \\
\text { Nacional Comum Curricular na Etapa do } \\
\text { Ensino Médio (BNCC-EM). } \\
\text { Homologa a versão final considerada para } \\
\text { este artigo. }\end{array}$ \\
\hline
\end{tabular}

Fonte: Quadro elaborado pelas autoras ${ }^{3}$. 
$\mathrm{Na}$ primeira fase de nosso estudo, realizamos a leitura das versões do documento e de pareceres de especialistas dados à primeira versão. Também foram examinados documentos relacionados, como a publicação realizada pelos membros do Grupo de Trabalho sobre Direitos à Aprendizagem e ao Desenvolvimento - GT DiAD (BONINI; DRUCK; BARRA, 2018) ${ }^{4}$. Posteriormente, na segunda fase, foram selecionados trechos a partir da recorrência e da centralidade que certos elementos assumiram, ao nosso ver, no decorrer da trama discursiva que institui o documento.

Daremos destaque, mesmo que brevemente, às modificações estruturais operadas nas versões destinadas ao Ensino Médio. No entanto, é importante destacar que foram realizadas em consonância com modificações observadas nas $1 .^{a}$ e 3 . $^{\text {a versões }}$ da BNCC voltadas à etapa do Ensino Fundamental. Para a Educação Infantil, a estrutura permaneceu modificando-se apenas o indicativo de idade mínima, que passou de 6 para 5 anos, como se observa no Quadro 2.

Quadro 2 - Comparação da estrutura geral - 1. a (BRASIL, 2015) e 3. a versões (BRASIL, 2017) - da BNCC voltada à Educação Infantil.

\begin{tabular}{|c|c|c|c|}
\hline & 1. a versão & \multicolumn{2}{|r|}{$\begin{array}{l}\text { 3. a versão homologada } \\
\text { (Resolução CNE/CP n. }{ }^{\circ} 2 \text { de } 22.12 .2017 \text { ) }\end{array}$} \\
\hline \multicolumn{4}{|c|}{ Educação Infantil } \\
\hline Idade & Campos de Experiência & Idade & Campos de Experiência \\
\hline \multirow{5}{*}{$\begin{array}{l}\text { Até } 6 \\
\text { anos }\end{array}$} & O eu, o outro e o nós & \multirow{5}{*}{$\begin{array}{l}\text { Até } 5 \\
\text { anos }\end{array}$} & O eu, o outro e o nós \\
\hline & Corpo, gestos e movimentos & & Corpo, gestos e movimentos \\
\hline & $\begin{array}{l}\text { Escuta, fala pensamento e } \\
\text { imaginação }\end{array}$ & & Escuta, fala, pensamento e imaginação \\
\hline & Traços, sons, cores e imagens & & Traços, sons, cores e formas \\
\hline & $\begin{array}{l}\text { Espaços, tempos, quantidades, } \\
\text { relações e transformações }\end{array}$ & & $\begin{array}{l}\text { Espaços, tempos, quantidades, relações } \\
\text { e transformações }\end{array}$ \\
\hline
\end{tabular}

Fonte: Quadro elaborado pelas autoras.

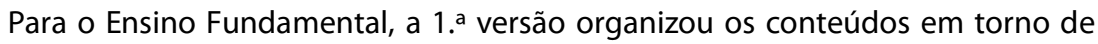
enfoques predominantes ${ }^{5}$, os quais foram formulados considerando-se o que nomeiam por identidades coletivas. Já na 3. ${ }^{a}$ versão, em oposição à 1. a, no que foi chamado por unidades temáticas, desloca-se a ênfase do coletivo para o individual, em clara referência a uma concepção de matriz liberal (o Eu Universal) (SANTOS, RIBEIRO, ONÓRIO, 2020). É o que observamos no rol voltado à etapa dos Anos Iniciais. 
SANTOS, M. A. L. dos; OLIVEIRA, A. R. L. de.

Quadro 3 - Comparação entre o rol de temáticas apresentado para os Anos Iniciais do Ensino Fundamental na 1. ${ }^{\mathrm{a}}$ (BRASIL, 2015) e 3. ${ }^{\text {a }}$ versões (BRASIL, 2017).

\begin{tabular}{|c|c|c|}
\hline & 1. a versão & $\begin{array}{c}3^{\text {a versão }} \\
\text { (homologada pela resolução CNE/CP n } 0^{\circ} 2 \text { de } \\
22.12 .2017 \text { ) }\end{array}$ \\
\hline \multicolumn{3}{|c|}{ Ensino Fundamental } \\
\hline & Enfoques predominantes & Unidades temáticas \\
\hline \multicolumn{3}{|l|}{ Série } \\
\hline $1 . .^{\circ}$ ano & Sujeitos e Grupos Sociais & $\begin{array}{l}\text { Mundo pessoal: meu lugar no mundo; Mundo } \\
\text { pessoal; eu, meu grupo social e meu tempo. }\end{array}$ \\
\hline $2 .^{\circ}$ ano & Grupos Sociais e Comunidades & $\begin{array}{l}\text { A comunidade e seus registros; } \\
\text { As formas de registrar as experiências da } \\
\text { Comunidade; O trabalho e a sustentabilidade da } \\
\text { Comunidade. }\end{array}$ \\
\hline $3 .^{\circ}$ ano & $\begin{array}{l}\text { Comunidades e outros lugares de } \\
\text { vivências }\end{array}$ & $\begin{array}{l}\text { As pessoas e os grupos que compõem a cidade e o } \\
\text { município; O lugar em que se vive; A noção de } \\
\text { espaço público e privado. }\end{array}$ \\
\hline $4 .^{\circ}$ ano & $\begin{array}{l}\text { Lugares de vivência e relações } \\
\text { sociais }\end{array}$ & $\begin{array}{l}\text { Transformações e permanências nas trajetórias dos } \\
\text { grupos humanos; Circulação de pessoas, produtos e } \\
\text { culturas; } \\
\text { As questões históricas relativas às Migrações. }\end{array}$ \\
\hline $5 .^{\circ}$ ano & Mundos brasileiros & $\begin{array}{l}\text { Povos e culturas: meu lugar no mundo e meu } \\
\text { grupo social; Registros da história: linguagens e } \\
\text { Culturas. }\end{array}$ \\
\hline
\end{tabular}

Fonte: Quadro elaborado pelas autoras (grifo nosso).

O mesmo ocorre com a etapa dos Anos Finais do Ensino Fundamental,

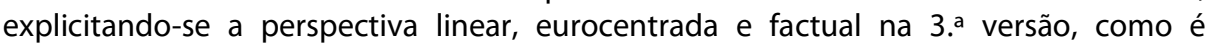
possível observar no Quadro 4.

Quadro 4 - Comparação entre o rol de temáticas apresentado para os Anos Finais do Ensino Fundamental nas 1. a (BRASIL, 2015) e 3. a versões (BRASIL, 2017).

\begin{tabular}{|c|c|c|}
\hline \multirow[t]{2}{*}{ Ano } & 1. ${ }^{\mathrm{a}}$ versão (2015) & $\begin{array}{c}\text { 3. } \text { a versão homologada }^{-} \\
\text {(Resolução CNE/CP n. } 2 \text { de } 20.12 .2017 \text { ) }\end{array}$ \\
\hline & Enfoques predominantes & Unidades Temáticas \\
\hline
\end{tabular}




\begin{tabular}{|l|l|l|}
\hline $6 .^{\circ}$ ano & $\begin{array}{l}\text { Representações, sentidos e } \\
\text { significados do tempo } \\
\text { histórico }\end{array}$ & $\begin{array}{l}\text { História: tempo, espaço e formas de registros; A } \\
\text { invenção do mundo clássico e o contraponto com } \\
\text { outras sociedades; lógicas de organização política; } \\
\text { trabalho e formas de organização social e cultural. }\end{array}$ \\
\hline $7 .^{\circ}$ ano & Processos e Sujeitos & $\begin{array}{l}\text { O mundo moderno e a conexão entre sociedades } \\
\text { africanas, americanas e europeias; Humanismos, } \\
\text { Renascimentos e o Novo Mundo; A organização do } \\
\text { poder e as dinâmicas do mundo colonial americano; } \\
\text { lógicas comerciais e mercantis da modernidade. }\end{array}$ \\
\hline $8^{\circ}$ ano & $\begin{array}{l}\text { Análise de processos } \\
\text { históricos }\end{array}$ & $\begin{array}{l}\text { O mundo contemporâneo: o Antigo Regime em crise; } \\
\text { Os processos de independência na Américas; O Brasil } \\
\text { no século XIX; Configurações do mundo no século } \\
\text { XIX; O nascimento da República no Brasil e os } \\
\text { processos históricos até a metade do século XX; } \\
\text { Totalitarismos e conflitos mundiais. }\end{array}$ \\
\hline $9 .^{\circ}$ ano & $\begin{array}{l}\text { Análise de processos } \\
\text { históricos }\end{array}$ & $\begin{array}{l}\text { Modernização, ditadura civil-militar } \\
\text { redemocratização: O Brasil após 1946; A história } \\
\text { recente. }\end{array}$ \\
\hline
\end{tabular}

Fonte: Quadro elaborado pelas autoras (grifo nosso).

Para esse segmento, de uma versão a outra, o rol de conteúdos conceituais e factuais, elencados como uma espécie de norteadores, aumenta tanto em número quanto em abrangência temporal, passando a abarcar longos períodos e processos históricos. Demonstra-se, na 3. a versão, uma preocupação em propor temáticas amplas, ordenadas segundo a periodização quadripartite (Idade Antiga, Moderna e Contemporânea, sem, no entanto, fazer clara referência ao período medieval), indicando que a ideia de uma "História Integrada" (Brasil e história europeia) ordena as relações entre História do Brasil e a chamada História Geral.

\section{RELAÇÕES RACIAIS E ENSINO DE HISTÓRIA SUBORDINADOS ÀS COMPETÊNCIAS}

Da 1. ${ }^{\text {a }}$ para a 3. ${ }^{\text {a }}$ versão voltada ao Ensino Médio, observamos mudanças mais radicais, como o abandono dos eixos temáticos que organizavam os conteúdos na primeira proposição. A BNCC para essa etapa foi totalmente reformulada, desconsiderando integralmente o trabalho realizado pelo GT-DiAD, cujo relatório mencionou-se anteriormente. $\mathrm{O}$ texto aprovado traz uma proposta que, em aparência, se contrapõe àquela configurada na $1 .^{\text {a }}$ versão, como é possível notar no quadro a seguir: 
SANTOS, M. A. L. dos; OLIVEIRA, A. R. L. de.

Quadro 5 - Quadro comparativo 1. a versão (BRASIL, 2015) e 3. a versão (BRASIL, 2018b) da BNCC voltadas à etapa do Ensino Médio

\begin{tabular}{|c|c|c|}
\hline \multirow[t]{4}{*}{ Série } & 1. a versão da BNCC (2015) & $\begin{array}{l}\text { 3.a versão da BNCC } \\
\text { (Homologada pela Resolução CNE/CP n॰ 4, de } 17 \text { de } \\
\text { dezembro de 2018) }\end{array}$ \\
\hline & Área de Ciências Humanas & \multirow[b]{2}{*}{ Área de Ciências Humanas e Sociais Aplicadas } \\
\hline & $\begin{array}{l}\text { Componente Curricular } \\
\text { História }\end{array}$ & \\
\hline & Enfoques predominantes & Competências Específicas \\
\hline $\begin{array}{c}1{ }^{\circ} \\
\text { ano }\end{array}$ & $\begin{array}{c}\text { Mundos ameríndios, } \\
\text { africanos e afro-brasileiros }\end{array}$ & \multirow[b]{3}{*}{$\begin{array}{l}\text { 1. Analisar processos políticos, econômicos, sociais, } \\
\text { ambientais e culturais nos âmbitos local, regional, } \\
\text { nacional e mundial em diferentes tempos, a partir da } \\
\text { pluralidade de procedimentos epistemológicos, } \\
\text { científicos e tecnológicos, de modo a compreender e } \\
\text { posicionar-se criticamente em relação a eles, } \\
\text { considerando diferentes pontos de vista e tomando } \\
\text { decisões baseadas em argumentos e fontes de natureza } \\
\text { científica. } \\
\text { 2. Analisar a formação de territórios e fronteiras em } \\
\text { diferentes tempos e espaços, mediante a compreensão } \\
\text { das relações de poder que determinam as as } \\
\text { territorialidades e o papel geopolítico dos Estados- } \\
\text { nações. } \\
\text { 3. Analisar e avaliar criticamente as relações de diferentes } \\
\text { grupos, povos e sociedades com a natureza (produção, } \\
\text { distribuição e consumo) e seus impactos econômicos e } \\
\text { socioambientais, com vistas à proposição de alternativas } \\
\text { que respeitem e promovam a consciência, a ética } \\
\text { socioambiental e o consumo responsável em âmbito } \\
\text { local, regional, nacional e global. } \\
\text { 4. Analisar as relações de produção, capital e trabalho em } \\
\text { diferentes territórios, contextos e culturas, discutindo o } \\
\text { papel dessas relações na construção, consolidação e } \\
\text { transformação das sociedades. } \\
\text { 5. Identificar e combater as diversas formas de injustiça, } \\
\text { preconceito e violência, adotando princípios éticos, } \\
\text { democráticos, inclusivos e solidários, e respeitando os } \\
\text { Direitos Humanos. } \\
\text { 6. Participar do debate público de forma crítica, } \\
\text { respeitando diferentes posições e fazendo escolhas } \\
\text { alinhadas ao exercício da cidadania e ao seu projeto de } \\
\text { vida, com liberdade, autonomia, consciência crítica e } \\
\text { responsabilidade. }\end{array}$} \\
\hline $\begin{array}{c}2^{\circ} \\
\text { ano }\end{array}$ & Mundos americanos & \\
\hline $\begin{array}{l}3^{\circ} \\
\text { ano }\end{array}$ & Mundos europeus e asiáticos & \\
\hline
\end{tabular}

Fonte: Quadro elaborado pelas autoras.

A mera disposição lado a lado daquilo que os documentos trazem em ambas as versões já se torna reveladora de alguns aspectos discursivos que gostaríamos de

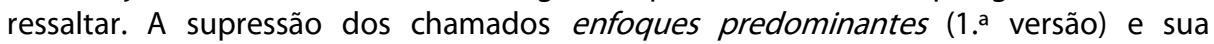
substituição pela listagem de competências (nomeadas no documento por competências específicas na $3 .^{\text {a }}$ versão) retira a ênfase da epistemologia do conhecimento histórico e a desloca para o que se pode fazer com ele. Temos, dessa 
forma, uma operação que, já presente na 1. ${ }^{a}$ versão, amplia-se de forma preponderante na 3. a instaurando uma cisão em que é possível perceber uma dualidade que posiciona, por um lado, o conhecimento em si, referindo-se aos conteúdos, e, por outro, o conhecimento para fazer algo, no que diz respeito às competências (MUNHOZ; OLEGÁRIO, 2019, p. 38). Esse elemento enuncia um aspecto pragmático que pode revelar uma concepção onde a Educação responde a um sistema educativo cujo conhecimento só tem sentido enquanto valor de troca (se for útil). Essa é a marca das reformas curriculares no Brasil e no exterior, pois:

\footnotetext{
O debate, insolúvel e ainda entendido por muitos, como central no campo do currículo, entre o conhecimento em si e o conhecimento para fazer algo é endereçado no formato de um currículo em camadas. De um lado, utilizam-se as disciplinas/matérias clássicas como fonte de conteúdos, tratados como conhecimento em si. De outro, assume-se que tais disciplinas não dão conta dos desafios contemporâneos e se propõem temas e, principalmente, capacidades transdisciplinares, para cujo atingimento $\mathrm{o}$ conhecimento é meio. Esse deslizamento é complementado pela referência a padrões de aprendizagem, demandados pela cultura da testagem em nível internacional (MACEDO, 2016, p. 54, grifo do autor).
}

Esse processo de transferência efetiva-se por movimentos de hibridação que, no caso específico do ensino de História, ocorrem pela aproximação dos aspectos cognitivos relacionados ao fazer do historiador, observada na versão homologada para o Ensino Fundamental, daqueles associados ao conceito de competências, subordinando o conhecimento histórico pela prevalência da cognição dos jovens e das ações cognitivas do cérebro humano em geral.

Nesse contexto discursivo, e acionando elementos dessa cadeia, a narrativa do documento aproxima a cognição histórica das chamadas competências específicas para o ensino de História também no Ensino Médio, tornando-se um híbrido que veicula, por isso, elementos de projetos díspares de formação e de Educação.

Para que esse processo de hibridação ocorresse, foi necessário operar dois apagamentos, de uma versão a outra. O primeiro deles refere-se ao lugar ocupado pela temática étnico-racial abordada em perspectiva intercultural na $1 .^{\text {a }}$ versão. Aqui, cabe observar os vários usos e sentidos que a perspectiva intercultural assume na contemporaneidade, podendo, por um lado, ser abordada como relacional ou funcional ao sistema dominante, quanto, por outro, ser "[...] concebida como proyecto político, social, epistémico y ético de transformación y decolonialidad" (WALSH, 2012, p. 62), como crítica ao capitalismo. Tais perspectivas apontam para projetos de sociedade díspares, sendo que a primeira vem sendo defendida em diferentes documentos de corte neoliberal, enquanto a segunda (a interculturalidade crítica) é defendida por diferentes movimentos sociais que preconizam o fim do capitalismo pela valorização de outros modos de ser e estar no mundo.

Embora muito tímida, a tentativa em estruturar uma organização dos conteúdos em enfoques predominantes conferindo centralidade à história dos negros e 
indígenas foi por nós considerada uma tentativa de tornar visíveis outras lógicas e formas de pensar, diferentes da lógica eurocêntrica. Por isso mesmo configurou-se como um indício de pensamento de fronteira na medida em que manteve como referência o pensamento dominante, mas fomentou seu questionamento (OLIVEIRA; CANDAU, 2010). Como estratégia, observamos aqui indícios de um projeto em que a interculturalidade é posicionada como princípio que orienta pensamentos, ações e novos enfoques epistêmicos, sendo concebida, nessa perspectiva, como processo e projeto político (OLIVEIRA; CANDAU, 2010).

Ao retirar a centralidade da temática étnico-racial do componente curricular de História, atribuindo-lhe um papel menor e periférico, subordinado a noções genéricas de cidadania e de diversidade, os formuladores da 3 . $^{a}$ versão produziram sentidos que buscaram hegemonizar a perspectiva de interculturalidade funcional operando uma "recontextualização por hibridismos que visam a legitimar certas vozes em detrimento de outras, formular consensos e orientar as mudanças para determinadas finalidades" (LOPES, 2005, p. 60).

Articulado a esse movimento, o segundo apagamento está relacionado à recontextualização operada pela substituição dos direitos de aprendizagem $e$ desenvolvimento ${ }^{6}$, fundamentos da articulação entre os componentes curriculares de

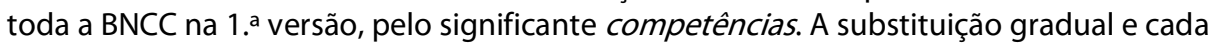
vez mais intensa do significante direitos pelo de competência é uma característica já perceptível na $3 .^{\text {a }}$ versão do documento, mas que foi explicitada textualmente nas Diretrizes Curriculares Nacionais para o Ensino Médio (DCNEM), cujo texto aponta:

\footnotetext{
Art. $6^{\circ}$ Para fins de obtenção de maior clareza de exposição ficam definidos os seguintes termos utilizados na presente Resolução: [...] VI - competências: mobilização de conhecimentos, habilidades, atitudes e valores, para resolver demandas complexas da vida cotidiana, do pleno exercício da cidadania e do mundo do trabalho. Para os efeitos desta Resolução, com fundamento no caput do art. 35-A e no $\S 1^{\circ}$ do art. 36 da LDB, a expressão "competências e habilidades" deve ser considerada como equivalente à expressão "direitos e objetivos de aprendizagem" presente na Lei do Plano Nacional de Educação (PNE). (BRASIL, 2018a, grifo nosso).
}

A centralidade do conceito de competências não é algo novo e está intensamente relacionado à Educação nas últimas décadas. Foi concebido nos meios empresariais estadunidenses na década de 1950 e, inicialmente, associado à ideia de melhoria da qualidade do serviço público como parte das estratégias de privatização. Essa associação serviu, ao longo dos anos da década de 1980 e 1990 em diferentes países do mundo, para justificar a adoção, por parte do setor público, de práticas gerencialistas oriundas do setor privado (PIOLLI; SILVA; HELOANI, 2015).

No Brasil, essa foi uma das marcas dos documentos curriculares forjados pelo Ministério da Educação no governo de Fernando Henrique Cardoso, sob a égide do qual se adotou "o pensamento pedagógico empresarial e as diretrizes dos organismos e das agências internacionais e regionais, dominantemente a serviço desse pensamento como diretriz e concepção educacional do Estado" (FRIGOTTO; CIAVATA, 2003, p. 108). A perspectiva pedagógica subjacente é marcada pelo individualismo e dualismo, 
corroborando com o ideário da desregulamentação, flexibilização e privatização e com o desmonte dos direitos sociais ordenados por uma perspectiva de compromisso social coletivo.

O modelo de gestão pautado em competências surge como resposta à crise de 1970, cuja causa, dentre outras, é o esgotamento do modelo de organização taylorista/fordista. Na busca por aumentar a produtividade e a competitividade das empresas, esse modelo, caracterizado pela produção em série, homogeneizada, com baixo desenvolvimento tecnológico e autoritário controle central, foi substituído pelo modelo toyotista, sinônimo de produção flexível, diversificada e enxuta, pautada no alto desenvolvimento tecnológico e organizacional, em poderes difusos e em modelos participativos de gestão (CARVALHO; SANTOS, 2016, p. 779). Essas mudanças passam a exigir um novo perfil de trabalhador, que deixa de realizar atividades prescritas e rotineiras para exercer tarefas diversificadas. Como consequência, deve ser flexível e apresentar um coquetel de competências (DELORS, 1998), ou seja, capacidades para se mobilizar diante de situações imprevistas.

A ideologia da gestão por competências, com foco na reorganização da produção, contou com a participação de estudiosos norte-americanos e anglo-saxões, dentre os quais alguns psicólogos, como McClelland, Skinner e Bloom e seu grupo, que contribuíram para a formulação de modelos avaliativos de pessoas e seus desempenhos (RAMOS, 2011). Extrapolando o mundo produtivo, chegou às escolas, ganhando status de pedagogia e tornando-se referência para a formulação de currículos, diretrizes, materiais didáticos, teorias educacionais (RAMOS, 2011) e matrizes de avaliação.

Nesse campo, o ideário das competências é posicionado em sinonímia com os epítetos de qualidade, equidade, eficácia e eficiência. Desse modo, práticas vinculadas ao discurso da "qualidade da educação" se naturalizam e se propagam como legítimas, ainda que suas raízes estejam calcadas em um sistema de objetivos, metas e resultados quantitativos e externos aos critérios e proposições do coletivo de professores (PIOLLI; SILVA; HELOANI, 2015). Assiste-se a subordinação progressiva da Educação "a objetivos econômicos, de empregabilidade, produtividade e competitividade, designadamente através dos discursos da qualidade e da excelência" (PIOLLI; SILVA; HELOANI, 2015, p. 594) e, ao acompanhar tendências mundiais, como é afirmando na BNCC, "reduzem a qualidade da educação à melhoria dos indicadores e posições em rankings, como o Programa Internacional de Avaliação de Estudantes (PISA)" (PIOLLI; SILVA; HELOANI, 2015, p. 594) ${ }^{7}$.

Assim, esse segundo apagamento, associado ao primeiro, mencionado anteriormente, permite observar como a tímida tentativa de estruturar uma proposta considerando as demandas apresentadas pelos movimentos sociais de indígenas e negros, operada em perspectiva decolonial e de interculturalidade crítica, é apagada por um projeto que, operando com híbridos, associa a diversidade e as relações raciais à promoção do diálogo, da convivência e da tolerância, mas não toca nas causas da assimetria e das desigualdades sociais e culturais (WALSH, 2012).

Por conseguinte, o apagamento das questões relacionadas à Educação para as relações raciais exacerba diferentes dimensões da colonialidade do saber e do poder, elemento que envolve diretamente a configuração de sentidos de identidade, de tempo 
SANTOS, M. A. L. dos; OLIVEIRA, A. R. L. de.

e de espaço, intrinsecamente relacionados ao sistema-mundo moderno-ocidental, o qual pressupõe a raça e o racismo como seus elementos estruturantes e constituintes (QUIJANO, 2005). Ou seja, em última instância, significa assumir uma produção historiográfica e um pensamento historiador marcados por essa colonialidade como elemento central e pilar da noção de tempo e de História que fundamenta esse documento curricular.

Aqui estaríamos diante de um dos alicerces fundamentais da BNCC: subordinar e controlar toda e qualquer produção intelectual que posicione em outro lócus narrativo. Portanto, que se posicione para além da sociedade que o sistema-mundo moderno capitalista quer impor como único possível.

\section{CONSIDERAÇÕES FINAIS}

A substituição dos chamados enfoques predominantes pelo rol de competências operada da $1^{a}$ para a $3^{a}$ versão voltada ao Ensino Médio é por nós considerada indício do processo de recontextualização que afasta o ensino de História tanto de sua função formativa quanto pedagógica e educativa ao exacerbar o pragmatismo, conforme apontamos. Assim, a abordagem das relações raciais, e a própria noção de ensino de História que se apresenta na BNCC, encontra-se "atravessada" por um conceito que, em si, foi transplantado de outras esferas do mundo do trabalho para aquele da Educação. Nesse sentido, é preciso considerar que o processo de elaboração da BNCC se deu em um contexto histórico peculiar, tendo sido, em um golpe, destituída a equipe inicial de formulação, levando-se "à encomenda, num gesto administrativo, de um documento que não fugisse ao script de uma cultura histórica canônica e, mais do que isso, que não gerasse dificuldades incontornáveis à formulação de itens para avaliação em largada escala" (MIRANDA, 2019, p. 89, grifo da autora).

Essa adaptação da BNCC às demandas do gerencialismo coadunou com os ataques perpetrados por historiadores ao documento utilizando-se do argumento:

\footnotetext{
de que uma criança brasileira tem o direito ao conhecimento da história da Humanidade escamoteia, na verdade, a ideia de que a história só se realiza a partir dos europeus, considerados 'civilizados', 'superiores' e, portanto, vistos como modelos de 'progresso' e de 'desenvolvimento' (SILVA; MEIRELLES, 2017, p. 9).
}

E esses ataques fortaleceram o projeto subjacente ao documento, porque, "curiosamente, o problema central inerente à formulação da BNCC - a concepção de avaliação em jogo na construção de uma proposta curricular de cunho nacional" (MIRANDA, 2019, p. 88), não fora objeto de críticas dos historiadores.

Para nós, abordar os conteúdos propostos ou mesmo analisar a abordagem das relações raciais sem observar essa subordinação é considerado inócuo, pois esse é o terreno sobre o qual se erige o projeto da BNCC, e ao qual a perspectiva de interculturalidade funcional se encontra em sintonia, contexto em que o ensino de História é colocado a serviço de projetos que pregam a mercantilização da Educação visando a supressão máxima do sistema público de ensino. 
Claro está que a identificação de híbridos na BNCC é acompanhada por ambivalências que produzem as negociações necessárias para garantir sua legitimação, ao mesmo tempo em que engendram zonas de escape dessa dominância (LOPES, 2005, p. 60).

Nesse sentido, à guisa de conclusão, ressaltamos que, como projeto político, seja do conjunto dos professores, seja dos movimentos sociais, em particular do Movimento Negro, a retomada das demandas que envolvem a temática da diversidade em sua interrelação com as relações raciais torna-se elemento fundamental em um projeto educativo que pretende formar para uma sociedade democrática. Para isso, ao restabelecermos a primazia das dimensões pedagógica e educativa, cada vez mais ocultadas e subordinadas nos documentos curriculares, sequestrada de todos os componentes, com destaque aqui para o de História, preconizamos que a formação integral e emancipadora dos sujeitos esteja pautada em uma perspectiva de interculturalidade crítica, a qual "pretende intervenir en y actuar sobre la matriz de la colonialidad, siendo esta intervención y transformación pasos esenciales y necesarios en la construcción misma de la interculturalidad" (WALSH, 2012, p. 66, grifo da autora).

Artigo recebido em: 19/12/2020

Aprovado para publicação em: 14/10/2021

\section{TEACHING HISTORY IN THE COMMON NATIONAL CURRICULAR BASE (BNCC): HYBRIDIZATION AND AFFIRMATION OF THE PERSPECTIVE OF FUNCTIONAL INTERCULTURALITY}

ABSTRACT: We present in this article, from a qualitative and documentary study, the analysis of some signifiers related to education for racial relations. These signifiers were approached as hybrids and gained prominence in the process of preparing the Common National Curriculum Base (BNCC). They pointed some concealment which are related with underlying political projects. We conclude by emphasizing that the replacement of the so-called predominant approaches, by the list of competences in the High School version, is configured as an indication of the recontextualization process. This process distances the teaching of History both from its formative, pedagogical and educational function, by exacerbating the pragmatism underlying the Pedagogy of Competences, the central foundation of the BNCC.

KEYWORDS: Educational Police. History Teaching. BNCC.

HISTORIA DOCENTE EN LA BASE COMÚN CURRICULAR NACIONAL (BNCC): HIBRIDACIÓN Y AFIRMACIÓN DE LA PERSPECTIVA DE LA INTERCULTURALIDAD FUNCIONAL

RESUMEN: Presentamos en este artículo, a partir de un estudio cualitativo y documental, el análisis de algunos significantes relacionados con la educación para las relaciones raciales que, abordados 
SANTOS, M. A. L. dos; OLIVEIRA, A. R. L. de.

como híbridos, se destacaron en el proceso de formulación del Currículo Base Común Nacional (BNCC) al señalar encubrimientos asociados con proyectos subyacentes. Concluimos destacando que la sustitución de los llamados enfoques predominantes por el listado de competencias en la versión de Bachillerato es un indicio del proceso de recontextualización que aleja la enseñanza de la Historia de su función formativa, pedagógica y educativa, al exacerbar la pragmatismo subyacente a la Pedagogía de Competencias, fundamento central del BNCC.

PALABRAS CLAVE: Políticas Curriculares. Enseñanza de la Historia. BNCC.

NOTAS

1 - O estudo a que nos referimos vincula-se ao projeto de pesquisa intitulado "Currículo e ensino de História: sentidos e significados de tempo passado raça, etnia e diversidade em propostas curriculares (2019/2020)", desenvolvido pela equipe do Grupo de Estudos e Pesquisas sobre Ensino de História e Práticas de Linguagem - Currículo, História e Cultura (GEPEH/UFMS).

2 - Investimento Direto Estrangeiro (SAWAYA, 2014).

3 - Em negrito identificamos os documentos que foram considerados para análise neste artigo.

4 - O Grupo de Trabalho sobre Direitos à Aprendizagem e ao Desenvolvimento (GT-DiAD), interdisciplinar e de participação popular, elaborou o documento de referência para a elaboração da Base Nacional Comum Curricular a partir dos Direitos à Aprendizagem e ao Desenvolvimento (BONINI; DRUCK; BARRA, 2018). Disponível em: https://acervodigital.ufpr.br/handle/1884/55911. Acesso em: 3 nov. 2021.

5 - "Cada ano escolar apresenta um enfoque predominante, mas não exclusivo, traduzido em títulos para facilitar a identificação de tal foco" (BRASIL, 2015, p. 242).

6 - O sentido de direitos de aprendizagem que foi gradualmente apagado pela recontextualização apontada aparece nesse trecho do documento elaborado pelo GT-DiAD: "Ao tratarmos do direito de aprender e de se desenvolver, buscamos a consolidação da dimensão social da educação na medida em que discutimos as oportunidades de desenvolvimento do educando, assegurando-lhe a formação comum imprescindível para o exercício da cidadania ao longo da vida em permanente produção de significados, ao mesmo tempo, oportunizando-lhe o aprofundamento constante dos conhecimentos e dos saberes adquiridos. É preciso, ainda, abrigar nessa dimensão social da educação o desenvolvimento do educador a partir de uma adequada formação humana, científica e cultural, e a efetivação de condições dignas de trabalho. Em consideração às expectativas de aprendizagem, como descritas nas Diretrizes Curriculares Nacionais, para além da perspectiva de um conjunto de obrigações imputadas somente aos estudantes para a consolidação das tarefas, finalidades e resultados escolares em um contexto de permanente culpabilização destes, de suas famílias e de seu contexto sociocultural, o MEC, no ano de 2012, assume trabalhar esse documento em uma perspectiva de direitos à aprendizagem e ao desenvolvimento. Esses direitos, por sua vez, ensejam o debate acerca das condições por meio das quais o Estado brasileiro tem garantido, ou não, condições para que as tarefas, finalidades e resultados escolares sejam efetivados de modo positivo na vida dos estudantes no cotidiano da instituição escolar" (BONINI; DRUCK; BARRA, 2018, p. 19-20, grifo nosso).

7 - Na atualidade, temos uma versão articulada aos princípios do PISA, que é o projeto SENNA (Social and Emotional or Non-cognitive Nation wide Assessment), "sigla inglesa que significa Avaliação Nacional Não-cognitiva ou Socioemocional (PRIMl; SANTOS, 2014). Esse modelo avaliativo, o próprio nome já enfatiza, está pautado em competências não cognitivas ou socioemocionais como, por exemplo, estabilidade emocional; conscienciosidade; extroversão; amabilidade e abertura a novas experiências, e está sendo formulado pelo Instituto Ayrton Senna, 
que conta com diversas parcerias com organizações internacionais e com o Ministério da Educação (MEC). Essa organização sem fins lucrativos integra, desde 2004, a rede de cátedras da Organização das Nações Unidas para a Educação, a Ciência e a Cultura (UNESCO), e realiza estudos na área de formação docente, avaliação e pedagogia para embasar políticas públicas por cerca de vinte anos. Para realizar essa grande variedade de trabalhos, o Instituto conta com recursos financeiros próprios e doações de pessoas físicas e empresas privadas. Hoje atende aproximadamente 75 mil professores, 2 milhões de alunos em 1200 municípios (PRIMI; SANTOS, 2014 apud CARVALHO; SANTOS, 2016, p. 777).

\section{REFERÊNCIAS BIBLIOGRÁFICAS}

BONINI, Adair; DRUCK, lole de Freitas; BARRA, Eduardo Salles de Oliveira (orgs.). Direitos à aprendizagem e ao desenvolvimento na Educação Básica: subsídios ao currículo nacional: no contexto dos debates para o estabelecimento da BNCC, elaborados no âmbito do Ministério da Educação entre dezembro de 2012 e fevereiro de 2015. Curitiba, GT DiAD-Grupo de Trabalho sobre Direitos à Aprendizagem e ao Desenvolvimento, 2018. Disponível em:

https://acervodigital.ufpr.br/bitstream/handle/1884/55911/direitos_a_aprendizagem_e _ao_desenvolvimento_na_educacao_basica_subsidios_ao_curriculo_nacionalpreprint.pdf?sequence=1\&isAllowed=y. Acesso em: 23 out. 2021.

BRASIL. Ministério da Educação. Base Nacional Curricular Comum. Educação é a Base. Base Nacional Comum Curricular. Primeira versão. Brasília: MEC, 2015. Disponível em: http://basenacionalcomum.mec.gov.br/images/relatorios-analiticos/BNCCAPRESENTACAO.pdf. Acesso em: 26 jun. 2020.

BRASIL. Ministério da Educação. Base Nacional Curricular Comum. Educação é a Base. Base Nacional Comum Curricular. Segunda versão. Brasília: MEC, 2016. Disponível em: http://basenacionalcomum.mec.gov.br/images/relatorios-analiticos/bncc.revista.pdf. Acesso em: 26 jun. 2020.

BRASIL. Ministério da Educação. Conselho Educacional de Educação. Conselho Pleno. RESOLUÇÃO CNE/CP No 2, DE 22 DE DEZEMBRO DE 2017. Resolução CNE/CP 2/2017. Diário Oficial da União, Brasília, 22 de dezembro de 2017, Seção 1, p. 41-44. Institui e orienta a implantação da Base Nacional Comum Curricular, a ser respeitada obrigatoriamente ao longo das etapas e respectivas modalidades no âmbito da Educação Básica. Brasília: MEC, 2017. Disponível em: http://basenacionalcomum.mec.gov.br/images/historico/RESOLUCAOCNE_CP222DEDE ZEMBRODE2017.pdf. Acesso em: 26 jun. 2020.

BRASIL. Resolução CNE-CEB n³, de 21 de novembro de 2018. Atualiza as Diretrizes Curriculares Nacionais para o Ensino Médio. Brasília: MEC, 2018a. Disponível em: 
SANTOS, M. A. L. dos; OLIVEIRA, A. R. L. de.

http://novoensinomedio.mec.gov.br/resources/downloads/pdf/dcnem.pdf. Acesso em: 19 jul. 2020.

BRASIL. Ministério da Educação. Conselho Educacional de Educação. Conselho Pleno. RESOLUÇÃO № 4, DE 17 DE DEZEMBRO DE 2018. Resolução CNE/CP 4/2018. Diário Oficial da União, Brasília, 18 de dezembro de 2018, Seção 1, p. 120-122. Institui a Base Nacional Comum Curricular na Etapa do Ensino Médio (BNCC-EM), como etapa final da Educação Básica, nos termos do artigo 35 da LDB, completando o conjunto constituído pela BNCC da Educação Infantil e do Ensino Fundamental, com base na Resolução CNE/CP no 2/2017, fundamentada no Parecer CNE/CP n 15/2017. Brasília: MEC, $2018 \mathrm{~b}$. Disponível em: http://portal.mec.gov.br/docman/dezembro-2018-pdf/104101-rcp00418/file. Acesso em: 26 jun. 2020.

BRASIL. Ministério da Educação. Base Nacional Curricular Comum. Educação é a Base. Base Nacional Comum Curricular. Terceira versão. Brasília: MEC, 2018c. Disponível em: http://basenacionalcomum.mec.gov.br/images/historico/BNCC_EnsinoMedio_embaixa_ site_110518.pdf. Acesso em: 26 jun. 2020.

CARVALHO, Elma Júlia Gonçalves de; SANTOS, Jane Eire Rigoldi. Políticas de avaliações externas: ênfase nas competências cognitivas e socioemocionais. Práxis Educativa, Ponta Grossa, v. 11, n. 3, p. 775-794, 2016. Disponível em: https://www.redalyc.org/journal/894/89446960014/html. Acesso em: 2 nov. 2021

DELORS, Jacques. Educação um tesouro a descobrir. Relatório para a UNESCO da Comissão Internacional sobre Educação para o século XXI. São Paulo: Editora Cortez, 1998.

FERRO, Marc. A história vigiada. São Paulo: Martins Fontes, 1989.

FRIGOTTO, Gaudêncio; CIAVATA, Maria. Educação Básica no Brasil na década de 1990: subordinação ativa e consentida à lógica do mercado. Revista Educ. Soc., Campinas, v. 24, n. 82, p. 93-130, abr. 2003.

GARCÍA CANCLINI, Néstor. Culturas híbridas: estratégias para entrar e sair da modernidade. São Paulo: EDUSP, 2015.

GHEDIN, Evandro; FRANCO, Maria Amélia Santoro. Questões de método na construção da pesquisa em Educação. São Paulo: Cortez Editora, 2011.

LOPES, Alice Casimiro. Os parâmetros curriculares nacionais para o ensino médio e a submissão ao mundo produtivo: o caso do conceito de contextualização. Educ. Soc., Campinas, v. 23, n. 80, p. 386-400, set. 2002.

LOPES, Alice Casimiro. Política de Currículo: Recontextualização e Hibridismo. Currículo sem Fronteiras, [s. I.], v. 5, n. 2, p. 50-64, jul./Dez. 2005.

Inter-Ação, Goiânia, v.46, n.3, p. 1378-1394, set./dez. 2021. Disponível em: <http://dx.doi.org/10.5216/ia.v46i3.67144>. 
LOPES, Alice Casimiro; MACEDO, Elizabeth. Teorias de Currículo. São Paulo: Cortez, 2011. Apoio Faperj.

MACEDO, Elizabeth. Currículo:Política, cultura e poder. Currículo sem Fronteiras, [s. I.], v. 6, n. 2, p. 98-113, jul./dez. 2006.

MACEDO, Elizabeth. Base nacional curricular comum: a falsa oposição entre conhecimento para fazer algo e conhecimento em si. Educ. rev., Belo Horizonte, v. 32, n. 2, p. 45-68, jun. 2016.

MENEZES, Fernando Vendrame. Indícios das práticas curriculares na disciplina de história em uma escola exemplar de Campo Grande entre 1942 e 1970. 2012. Dissertação (Mestrado em Educação) - Faculdade de Educação, Universidade Federal de mato Grosso Sul, Campo Grande, 2012.

MUNHOZ, Angélica Vier; OLEGÁRIO, Fabiane. Base Nacional Comum Curricular: tensionamentos, invenção e transcriação. In:SILVA, Fabiany de Cássia Tavares; XAVIER FILHA, Constantina (org.). Conhecimentos em disputa na Base Nacional Comum Curricular. Campo Grande: Editora Oeste, 2019. p. 33-53.

OLIVEIRA, Luiz Fernandes de; CANDAU, Vera Maria Ferrão. Pedagogia decolonial e educação antirracista e intercultural no Brasil. Educação em Revista, Belo Horizonte, v. 26, n. 1, p. 15-40, abr. 2010.

PIOLLI, Evaldo; SILVA, Eduardo Pinto e; HELOANI, José Roberto M. Plano Nacional de Educação, Autonomia Controlada e Adoecimento do Professor. Cad. Cedes, Campinas, v. 35, n. 97, p. 589-607, set./dez., 2015.

QUIJANO, Aníbal. Colonialidade do poder, Eurocentrismo e América Latina. In:LANDER, Edgardo (org.). A colonialidade do saber: eurocentrismo e ciências sociais. Perspectivas latino-americanas. CLACSO, Consejo Latinoamericano de Ciencias Sociales, Ciudad Autónoma de Buenos Aires, Argentina, set. 2005. p. 227-278. Disponível em:

http://biblioteca.clacso.edu.ar/clacso/sur-sur/20100624103322/12_Quijano.pdf. Acesso em: 23 out. 2021.

RAMOS, M. N. A pedagogia das competências: autonomia ou adaptação? 4. ed. São Paulo: Cortes, 2011.

SÁ-SILVA. Jackson Ronie; ALMEIDA, Cristóvão Domingos de; GUINDANI, Joel Felipe. Pesquisa documental: pistas teóricas e metodológicas. Revista Brasileira de História \& Ciências Sociais, Rio Grande, Ano I - Número I, p. 1-15, julho de 2009. ISSN: 2175-3423. Disponível em: https://periodicos.furg.br/rbhcs/article/view/10351. Acesso em: 15 dez. 2021. 
SANTOS, M. A. L. dos; OLIVEIRA, A. R. L. de.

SAWAYA, Rubens. Poder econômico, desenvolvimento e neoliberalismo no Brasil. Revista da Sociedade Brasileira de Economia Política, Niterói, [s. v.], n. 39, p. 124-149, out. 2014.

SANTOS, Maria Aparecida Lima dos; RIBEIRO, Suzana Lopes Salgado; ONÓRIO, Wanessa Odorico. Ensino de História na Base Nacional Comum Curricular (BNCC): sentidos de diversidade nos Anos Iniciais. Revista Política e Gestão Educacional, Araraquara-SP, v. 24, n. especial 2, p. 961-978, set.-dez. 2020. Disponível em:

https://periodicos.fclar.unesp.br/rpge/article/view/14326/9795. Acesso em: 23 out. 2021.

SILVA, Giovani José da; MEIRELES, Marinelma Costa. Orgulho e preconceito no ensino de História no Brasil: reflexões sobre currículos, formação docente e livros didáticos. Crítica Histórica, Alagoas, v. 8, n. 15, p. 7-30, 2017.

WALSH, Catherine. Interculturalidad y (de)colonialidad: Perspectivas críticas y políticas. Visão Global, Joaçaba, v. 15, n. 1-2, p. 61-74, jan./dez. 2012.

Maria Aparecida Lima dos Santos: Professora Associada da Faculdade de Educação (FAED) da Universidade Federal do Mato Grosso do Sul (UFMS). Docente do Programa de Pós-Graduação em Educação (PPGEDU/UFMS) e do Programa de PósGraduação Mestrado Profissional em Ensino de História (PROFHistória/UEMS).

Orcid: https://orcid.org/0000-0001-8106-4978

E-mail:maria.lima-santos@ufms.br

Ana Rita Lara de Oliveira: Mestranda do Programa de Pós-Graduação em Educação, da Faculdade de Educação (FAED) - Universidade Federal do Mato Grosso do Sul (UFMS).

Orcid: https://orcid.org/0000-0003-1586-930X

E-mail: anaritaoliveiraufms@gmail.com

Este periódico utiliza a licença Creative Commons Attribution 3.0, para periódicos de acesso aberto (Open Archives Initiative - OAI). 